\title{
Community violence and alcohol abuse among adolescents: a sex comparison
}

\author{
Taís C. Moreira, ${ }^{1}$ Elisa L. Belmonte, ${ }^{2}$ Fernanda Rodrigues Vieira, ${ }^{3}$ \\ Ana Regina Noto, ${ }^{4}$ Maristela Ferigolo, ${ }^{5}$ Helena M. T. Barros ${ }^{6}$
}

\begin{abstract}
Objective: To verify whether there is an association between victimization and alcohol use among boys and girls in Porto Alegre, RS, Brazil.

Methods: This was a cross-sectional study of students from public schools, aged 10 to 19 years, from the fifth grade of primary education to the third grade of secondary education, selected by two-stage cluster sampling, defined by the socioeconomic characteristics of the neighborhood in which each school is located and by school class. Data collection was by means of a questionnaire which was completed anonymously and voluntarily.

Results: Fifty-four percent of the older adolescent boys (aged 14-19) drank alcohol, compared to $17 \%$ of the younger adolescent boys (10-13), as did 58\% of the older adolescent girls and $19 \%$ of the younger adolescent girls. Fifty-seven percent of the students had suffered severe victimization, and $53 \%$ had suffered moderate victimization. When the samples were separated by sex, it was observed that boys and girls who drank alcohol reported 2.6 and 1.8 times more severe victimization respectively, while alcohol was associated with 3.1 and 2.5 times greater prevalence of moderate victimization, among boys and girls respectively. When episodes of drunkenness were analyzed, it was observed that adolescents got drunk more than pre-adolescents and that exposure to violence exhibited an increased association with drunkenness. Thirty-two percent of the boys (prevalence ratio, $\mathrm{PR}=4.4 ; 95 \% \mathrm{CI} 2.6-7.3$ ) and $22 \%$ of the girls ( $P R=2.2 ; 95 \% C I 1.2-4.1)$ who had been the victims of severe violence reported being drunk at least once.
\end{abstract}

Conclusions: Adolescents of both sexes who consume more alcohol are at greater risk of suffering community violence.

J Pediatr (Rio J). 2008;84(3):244-250: Community violence, alcohol, adolescents.

\section{Introduction}

Violence is recognized worldwide as being a social and public health issue. Considering the perpetrator, violence can be classified as self-inflicted, interpersonal or collective. ${ }^{1}$ Interpersonal violence includes domestic and community violence. The first normally takes place between family members or intimate partners, and the second between unrelated people, who may or may not know each other. Sexual violence by strangers, violence in school, at work, on the streets, in prisons and retirement homes are all examples of community violence. ${ }^{1}$ In Brazil there is a high rate of crime involving violence against young people. Almost $100 \%$ of students in the state education system in Porto Alegre have been exposed to some type of violence, $70 \%$ as the victims of one or more incidents, while $98 \%$ have witnessed violent acts. ${ }^{2}$

1. Fonoaudióloga. Mestre, Fundação Universidade Federal de Ciências da Saúde de Porto Alegre (UFCSPA), Porto Alegre, RS, Brazil.

2. Farmacêutica. Mestre, UFCSPA, Porto Alegre, RS, Brazil.

3. Acadêmica de Psicologia, Universidade Luterana do Brasil (ULBRA), Canoas, RS, Brazil.

4. Doutora, Universidade Federal de São Paulo (UNIFESP), São Paulo, SP, Brazil.

5. Doutora, UFCSPA, Porto Alegre, RS, Brazil.

6. Pós-Doutorado em Neuropsicofarmacologia, UFCSPA, Porto Alegre, RS, Brazil.

Financial support: This research was partially funded by CEBRID and AAPEFATO/SENAD.

No conflicts of interest declared concerning the publication of this article.

Suggested citation: Moreira TC, Belmonte EL, Vieira FR, Noto AR, Ferigolo M, Barros HM. Community violence and alcohol abuse among adolescents: a sex comparison. J Pediatr (Rio J). 2008;84(3):244-250.

Manuscript received Nov 26 2007, accepted for publication Feb 272008.

doi:10.2223/JPED.1795 
Many studies have demonstrated a relationship between drinking alcohol and violent behavior. ${ }^{3-6}$ Alcohol facilitates violence and there are associations between being under the influence of alcohol and participation in homicides, suicides, domestic violence, sexual crimes and traffic accidents, both as victims and perpetrators of violent acts. ${ }^{6,7}$ Consumption of alcohol is also associated with drowning, delinquency and reduced performance at school. ${ }^{7,8}$ Nevertheless, the relationship between alcohol consumption and violence is complex, since there is not a simple unidirectional association. ${ }^{9}$ There is a significant association between interpersonal violence, including community violence, and consumption of alcoholic drinks and/or other drugs, both by those inflicting the violence and their victims. ${ }^{10}$ This association becomes more and more intense the greater the quantity of alcohol consumed. ${ }^{5,11}$ The association between alcohol consumption and violence is also illustrated by the results of campaigns to reduce alcohol use, which favor a reduction in the rates of violence and/or homicide. ${ }^{5,9}$

International studies of young populations with violent behavior have suggested that the presence of alcohol, other drugs and weapons increases the probability of violence resulting in severe injuries and deaths. ${ }^{1,4-6}$ Fewer studies have been carried out in Brazil into the association between the use of psychoactive drugs and violence among young people. ${ }^{12}$ Alcohol is the drug that is most often taken by young people. ${ }^{13}$ The effects of alcohol are more prejudicial to adolescents than to adults, since it impairs judgment and the ability to recognize danger, making it difficult to understand risks. ${ }^{1}$ Among young people, alcohol consumption makes individuals more likely to take part in delinquent behavior, becoming the victims or perpetrators of community violence. ${ }^{6}$

The majority of studies of community violence describe significant differences between the sexes, with boys exposed to more violence than girls. ${ }^{6}$ One of the reasons why more violence takes place between males could be due to the fact that they take more drugs and drink more alcohol. ${ }^{13}$ However, the majority of studies into this area have related alcohol/drug use with perpetration of community violence. The association between victimization and use/abuse of alcohol by adolescents has not yet been described in the Brazilian population, and studies differentiating the sexes are also rare.

The recent increase in rates of use and abuse of alcohol by young people, particularly among females, ${ }^{13}$ demonstrates the need for studies relating violent victimization with systematic or abusive use of alcohol by young people. The objective here was to determine whether there is a similar association between victimization, community violence and alcohol abuse or drunkenness among male and female students in the public education system and also to investigate associated factors.

\section{Methods}

This was a cross-sectional epidemiological survey of students aged 10 to 19 years at public schools in Porto Alegre,
RS, Brazil during the second half of 2003, as part of the Fifth National Survey of Psychoactive Drug Use Among Students (V Levantamento Nacional Sobre Uso de Drogas Psicotrópicas entre Estudantes). ${ }^{14}$ Subjects were selected by means of two-stage cluster sampling, taking the school class as sampling unit. The sample size was calculated using a formula that related research costs to first and second-stage units and a coefficient of homogeneity. Combinations were therefore calculated that would result in an ideal sample size of between 1,500 and 2,500 questionnaires, distributed across five to 20 schools, with a minimum of four classes per school. The public schools in Porto Alegre were registered in advance and divided into strata representative of their neighborhoods as defined by their socioeconomic characteristics, represented by the family incomes in each school's neighborhood calculated in multiples of the monthly minimum wage ( $<5 \mathrm{MMW} ; 5$ to $20 \mathrm{MMW}$; > $20 \mathrm{MMW}$ ) and the basic sanitation infrastructure of each neighborhood (treated water supply, sewage and drainage systems). Participating schools were selected by lots, first taking account of neighborhood infrastructure and then whether they studied in the morning, afternoon or evening. ${ }^{14}$

Data collection was carried out by six researchers. ${ }^{14}$ Questionnaires were administered simultaneously and collectively in the classroom, with no teacher present. The students were informed of the anonymous and voluntary nature of the study. The Research Ethics Committee at the Universidade Federal de São Paulo evaluated and approved the project (CEP no. $0718 / 03$ ). Double input data entry was used in order to detect and correct typing errors. The instruments employed included the following questionnaires: 1 ) World Health Organization (WHO) questionnaire on drug use, translated and adapted for use in Brazil by Galduróz et al. ${ }^{14}$ and used in all national surveys into drug use among Brazilian students; and 2) survey of children exposed to violence, ${ }^{2,15}$ both employed in recent studies in Brazil. ${ }^{2,14,15}$ Alcohol consumption was categorized into use during the previous month, if an individual had drunk alcohol at least once during the 30 days prior to the research, reflecting systematic use. Drunkenness during the month was defined as when the student answered yes to the question, "During the last month, have you drunk alcohol until you got drunk?" Answers to items on the questionnaire referring to physical violence victimization were used, ${ }^{2}$ grouping together items relating to severe victimization ("I have been sexually attacked or molested; I have been attacked or stabbed with a knife or injured in a violent incident; I have been shot ") and items relating to moderate victimization (" I was at home during a burglary, I have been picked up, arrested or taken away by the police; I have been threatened with severe physical injury by someone; I have been beaten or robbed"), since principal component analysis proved that together they possessed significant dimensions for describing the exposure of adolescents to violence. ${ }^{16}$ Respondents aged 10 to 13 years of age were defined as younger adolescents, and those aged 14 to 19 years as older adolescents. 
This separation was due to the fact that the younger age group is more susceptible to bullying, ${ }^{17}$ while having lower drug consumption. ${ }^{18}$

A total of 2,039 questionnaires were administered at 20 schools. Individuals were included if they filled in both questionnaires and excluded if they did not provide their age or sex or if more than four questions had been voided or if they claimed to use a fictitious drug. In all, 209 questionnaires were excluded based on the criteria above. Initially, descriptive analyses were performed of age group, educational level, sex, neighborhood infrastructure, moderate and severe victimization and alcohol use and drunkenness during the previous month. Bivariate statistical analyses were carried out using the chi-square test, in order to detect associations with statistical significance between the variables alcohol use and drunkenness and the sociodemographic variables, and also moderate and severe victimization, both for the sample as a whole and broken down by sex. Prevalence ratios (PR) and their respective confidence intervals $(95 \% \mathrm{CI})$ were used to measure associations in these analyses. In order to confirm associations and to control possible confounding factors, a logistic regression analysis was performed, including sociodemographic variables and moderate and severe victimization for the dependent variables alcohol use or drunkenness during the month, with separate samples for each sex. The Statistical Package for Social Sciences (SPSS, 12.0) was used and the significance level was set at $p<0.05$.

\section{Results}

Table 1 provides the demographic characteristics of the sample after exclusions, together with alcohol use and drunkenness during the month and severe and moderate violence. Overall, $39 \%$ of the students had drunk alcohol during the previous 30 days and $12 \%$ had been drunk at least once during the month; $43 \%$ reported having been subjected to moderate community violence and $10 \%$ to severe violence.

While $54 \%$ of the older adolescents ( 14 to 19 ) drank alcohol, consumption reduced to $17 \%$ among the younger boys. It is of note that older adolescents drank alcohol five times as much is adolescents aged 10 to 13 years. With relation to the girls, $58 \%$ of the older adolescents and $19 \%$ of the younger adolescents drank alcohol, similar to the data for the boys. When students were compared by educational level, it was observed that $30 \%$ of the students in primary education and $63 \%$ of the students in secondary education had drunk alcohol during the previous 30 days, without differentiating between the sexes. The infrastructure of the neighborhoods in which the schools were located did not prove to be a factor relevant to alcohol consumption. It was observed that $42 \%$ of the boys and $43 \%$ of the girls who drank alcohol studied in a school located in a good neighborhood, which could not be differentiated statistically from the $36 \%$ of boys and $37 \%$ of girls who drank alcohol and attended school in neighborhoods with infrastructure considered poor (Table 2 ).
Students who described using alcohol had twice the probability of severe victimization and almost three time the probability of moderate victimization (Table 2 ). When the sample was separated by sex, it was observed that boys and girls who drank alcohol reported 2.6 and 1.8 times more severe victimization, respectively, while using alcohol was associated with 3.1 and 2.5 times greater prevalence of moderate victimization among boys and girls, respectively. However, when adjustments were made for confounding variables using logistic regression (Table 2), it was detected that factors such as adolescence have an important association with alcohol consumption ( $p<0.001)$ and that moderate victimization, but not severe victimization, was associated with alcohol consumption, both for boys and girls.

With relation to episodes of alcoholic intoxication (Table 3 ), it is of note that the older adolescents got drunk four times more than the younger adolescents (10 to 13 ). Analyzing data on drunkenness, $17 \%$ of the older adolescents reported getting drunk, compared with $5 \%$ of the younger adolescents. In common with alcohol use, drunkenness was two to three times more prevalent among students in secondary education, being reported by $20 \%$ of the boys and $19 \%$ of the girls. The infrastructure of the neighborhood in which each school was located did not have a significant relationship with episodes of problematic alcohol use. Bivariate analyses of exposure to violence indicated a three times greater association between drunkenness and moderate/severe victimization. A statistically greater percentage of drunkenness and victimization was observed among boys (32\%) than among girls (17\%, p < $0.05)$. Girls (17\%) and boys (18\%) who reported drunkenness were victims of moderate violence, with similar and significant prevalence ratios. The logistic regression analysis demonstrated that later adolescence (14 to 19) was associated with drunkenness and moderate victimization in both sexes and that there was an association between drunkenness and severe victimization among the boys only (Table 3 ).

\section{Discussion}

This study detected a significant association between alcohol abuse and being the victim of community violence among Brazilian students of both sexes in secondary education and in the final grades of primary education.

Alcohol consumption rates among young Brazilians are extremely high, with experimental alcohol consumption among students aged 12 to 18 years at around $70 \%$, being discretely more elevated among girls than boys. ${ }^{14}$ Although in Brazil it is illegal to sell alcoholic beverages to people less than 18 years old, it can be observed that alcohol is used and abused by a large number of adolescents, who do not appear to have problems acquiring it. ${ }^{19,20}$

Adolescents aged 14 to 19 years consume and abuse alcohol more than adolescents aged 10 to $13 .^{20,21}$ This association explains why secondary education students consume 
Table 1 - Demographic characteristics, use of alcohol during the month, drunkenness during the month and victimization among students from the public education system of Porto Alegre, Brazil, 2003

\begin{tabular}{cccc}
\hline & Overall & Girls & Boys \\
Characteristics & $(n=1,830 *)$ & $(n=968 *)$ & $(n=862 *)$
\end{tabular}

Age group of the adolescents

$\begin{array}{llll}10 \text { to } 13 \text { years } & 818(45 \%) & 451(47 \%) & 367(43 \%) \\ 14 \text { to } 19 \text { years } & 1,012(55 \%) & 517(53 \%) & 495(57 \%)\end{array}$

Educational level

Primary education

$1,314(72 \%)$

$516(28 \%)$

$685(71 \%)$

$629(73 \%)$

Secondary education

Neighborhood infrastructure

Good

$826(45 \%)$

$1,004(55 \%)$

$712(43 \%)$

$951(57 \%)$

$327(37 \%)$

$385(50 \%)$

No

Severe victimization ${ }^{+\S}$

Yes

$168(10 \%)$

$74(8 \%)$

$94(11 \%)$

No

$1,459(90 \%)$

$807(91 \%)$

$652(76 \%)$

Drank alcohol this month ${ }^{+}$

Yes

$705(39 \%)$

$1,094(61 \%)$

$379(40 \%)$

$326(38 \%)$

No

Been drunk this month ${ }^{\dagger}$
Yes

$214(12 \%)$

$1,598(88 \%)$

$114(12 \%)$

$100(12 \%)$

No
$850(88 \%)$

* Data presented in absolute numbers (percentage).

† Some of the Interviewees did not answer the questions relating to the variables moderate and severe victimization, alcohol use and drunkenness during the month.

${ }^{\ddagger}$ Moderate victimization refers to "I was at home during a burglary, I have been picked up, arrested or taken away by the police; I have been threatened with severe physical injury by someone; I have been beaten or robbed".

$\S$ Severe victimization refers to "I have been sexually attacked or molested; I have been attacked or stabbed with a knife or injured in a violent incident; I have been shot".

more alcoholic drinks than primary school students, i.e. because they are older. ${ }^{22,23}$ This observation is similar to what has been described with relation to drugs of abuse. ${ }^{18}$

Data from the adult Brazilian population demonstrate that men consume more alcohol than women. The data from adults also demonstrate that there is more community violence victimization among men. ${ }^{24}$ However, in this study it was found that among adolescents there are no differences between the sexes in terms of alcohol use, irrespective of whether alcohol consumption or drunkenness is being considered. The most important result found in this study relate the risks of alcohol 
Table 2 - Prevalence ratios for alcohol use during the month among students from the public education system of Porto Alegre, Brazil (2003): results of raw and multivariate analyses*

\begin{tabular}{|c|c|c|c|c|c|c|c|c|}
\hline \multirow[b]{3}{*}{ Alcohol use this month } & \multicolumn{4}{|c|}{ Boys } & \multicolumn{4}{|c|}{ Girls } \\
\hline & \multirow[b]{2}{*}{$\mathrm{n}^{+}$} & \multicolumn{2}{|c|}{ Raw } & \multirow{2}{*}{$\begin{array}{c}\text { Adjusted } \\
\text { PR }(95 \% \mathrm{CI})\end{array}$} & \multirow[b]{2}{*}{$\mathbf{n}^{+}$} & \multicolumn{2}{|c|}{ Raw } & Adjusted \\
\hline & & $n^{*}(\%)^{\S}$ & PR $(95 \% \mathrm{CI})$ & & & $n^{\neq}(\%)^{\S}$ & PR $(95 \% \mathrm{CI})$ & PR $(95 \% \mathrm{CI})$ \\
\hline
\end{tabular}

Age group of adolescents

$\begin{array}{lllllllll}14 \text { to } 19 \text { years } & 360 & 264(54 \%) & 5.6(4.2-7.6)^{\prime \prime} & 3.4(2.2-5.2)^{\prime \prime} & 443 & 293(58 \%) & 5.6(4.2-7.6)^{\prime \prime} & 4.6(3.1-6.9)^{\prime \prime} \\ 10 \text { to } 13 \text { years } & 488 & 62(17 \%) & - & - & 508 & 86(19 \%) & - & -\end{array}$

Educational level

Primary education

Secondary education
$611176(64 \%)$

$233148(29 \%)$

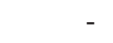

$4.3(3.2-5.9)^{1 \mid}$

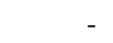

$1.9(1.2-2.8)^{11}$
$674209(31 \%)$

$274169(62 \%) \quad 3.6(2.6-4.8)^{\prime \prime}$

$1.3(0.8-1.9)$

Neighborhood infrastructure

$\begin{array}{lllllllll}\text { Good } & 394 & 165(42 \%) & 1.3(0.9-1.7) & 1.3(0.9-1.8) & 419 & 181(43 \%) & 1.3(0.9-1.6) & 1.2(0.8-1.6) \\ \text { Poor } & 454 & 161(36 \%) & - & - & 532 & 198(37 \%) & - & -\end{array}$

Moderate victimization

Yes

No

Severe victimization

Yes

No

$$
380195(51 \%)
$$$$
3.1(2.2-4.1)^{\prime \prime}
$$$$
1.8(1.3-2.6)^{11}
$$$$
32
$$$$
38299(26 \%)
$$$$
55
$$

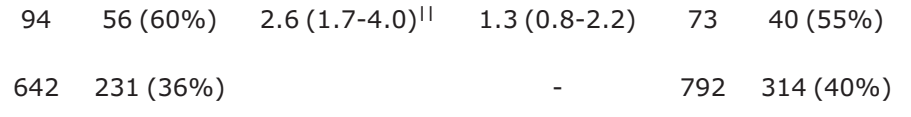

$642 \quad 231(36 \%)$

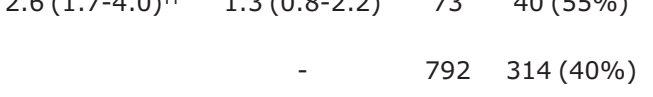

$95 \% \mathrm{CI}=95 \%$ confidence interval; PR = prevalence ratio.

* Age group, educational level, neighborhood infrastructure, moderate and severe victimization.

+ Total number of replies to each question.

* Students who reported drinking alcohol during the last month, according to each variable.

$\S$ Percentages calculated based on the total number of people providing responses to each questions $\left({ }^{\dagger}\right)$.

II $\mathrm{p}<0.05$.

use to moderate and severe community violence victimization, for both boys and girls, at similar levels as observed in other countries. ${ }^{16,25}$ Alcohol appears to increase vulnerability to victimization, irrespective of the type of violent behavior. ${ }^{5}$ Although our findings indicate small differences between the sexes in violent events and alcohol consumption or abuse, the boys had suffered higher rates of certain types of violence than girls. Severe victimization events were strongly associated with drunkenness for boys but not for girls. These findings are in agreement with other studies, ${ }^{6,16}$ in which male adolescents in older age groups were more often victimized than female older adolescents. It is possible that this association is related to the fact that the girls used more legal and illegal drugs ${ }^{16}$ after traumatic events, in addition to the psychological consequences occurring differently for girls and for boys. Girls exhibit more symptoms of posttraumatic stress after direct or indirect exposure to violence. ${ }^{26}$ However a causal relationship between these two events needs to be explored further in the future.

The relationship between violence and alcohol consumption is not a simple unidirectional causal one, which results in certain limitations to this study. ${ }^{9}$ Adolescents exposed to violence exhibit high rates of tobacco, alcohol and marijuana consumption and, consequently, are more susceptible to the use of illicit drugs. ${ }^{16}$ Another possible limitation is the fact that associations depend on how interactions are observed. In a British community, between 2003 and 2004, it was demonstrated that the perpetrators of violence had used alcohol in $50 \%$ of all violent incidents, meaning an equal number of violent incidents were not associated with alcohol. ${ }^{27}$ Despite all of the methodological precautions adopted in this study it is 
Table 3 - Prevalence ratios for drunkenness during the month among students from the public education system of Porto Alegre, Brazil (2003): results of raw and multivariate analyses*

\begin{tabular}{|c|c|c|c|c|c|c|c|c|}
\hline \multirow[b]{3}{*}{ Drunkenness this month } & \multicolumn{4}{|c|}{ Boys } & \multicolumn{4}{|c|}{ Girls } \\
\hline & \multirow[b]{2}{*}{$\mathbf{n}^{+}$} & \multicolumn{2}{|c|}{ Raw } & \multirow{2}{*}{$\begin{array}{c}\text { Adjusted } \\
\text { PR }(95 \% C I)\end{array}$} & \multirow[b]{2}{*}{$\mathbf{n}^{+}$} & \multicolumn{2}{|c|}{ Raw } & \multirow{2}{*}{$\begin{array}{c}\text { Adjusted } \\
\text { PR }(95 \% \mathrm{CI})\end{array}$} \\
\hline & & $n^{*}(\%)^{\S}$ & PR (95\%CI) & & & $n^{*}(\%)^{\S}$ & PR (95\%CI) & \\
\hline \multicolumn{9}{|l|}{ Age group of the adolescents } \\
\hline 14 to 19 years & 490 & $83(17 \%)$ & $4.1(2.3-7.0)^{11}$ & $2.4(1.2-4.8)^{\prime \prime}$ & 514 & $93(18 \%)$ & $4.5(2.7-7.3)^{11}$ & $4.6(2.2-9.2)^{11}$ \\
\hline 10 to 13 years & 358 & $17(5 \%)$ & - & - & 450 & $21(5 \%)$ & - & - \\
\hline \multicolumn{9}{|l|}{ Educational level } \\
\hline Primary education & 613 & $47(8 \%)$ & - & - & 681 & $60(9 \%)$ & - & - \\
\hline Secondary education & 231 & $52(20 \%)$ & $2.7(1.7-4.2)^{\prime \prime}$ & $0.6(0.3-1.0)$ & 280 & $53(19 \%)$ & $2.4(1.6-3.6)^{\prime \prime}$ & $0.9(0.5-1.4)$ \\
\hline \multicolumn{9}{|l|}{ Neighborhood infrastructure } \\
\hline Good & 392 & $51(13 \%)$ & $1.2(0.8-1.8)$ & $1.3(0.8-2.2)$ & 424 & $46(11 \%)$ & $0.9(0.5-1.3)$ & $0.8(0.5-1.3)$ \\
\hline Poor & 456 & $49(11 \%)$ & - & - & 540 & $68(12 \%)$ & - & - \\
\hline \multicolumn{9}{|l|}{ Moderate victimization } \\
\hline Yes & 380 & $69(18 \%)$ & $3.4(2.1-5.7)^{11}$ & $2.1(1.2-3.7)^{\prime \prime}$ & 326 & $56(17 \%)$ & $2.5(1.6-3.8)^{\prime \prime}$ & $1.7(1.1-2.7)^{\prime \prime}$ \\
\hline No & 384 & $23(6 \%)$ & - & - & 561 & $43(7 \%)$ & - & - \\
\hline \multicolumn{9}{|l|}{ Severe victimization } \\
\hline Yes & 94 & $30(32 \%)$ & $4.4(2.6-7.3)^{\prime \prime}$ & $2.5(1.3-4.6)^{\prime \prime}$ & 74 & $16(22 \%)$ & $2.2(1.2-4.1)^{\prime \prime}$ & $1.2(0.6-2.3)$ \\
\hline No & 644 & $62(9 \%)$ & - & - & 804 & $88(11 \%)$ & - & - \\
\hline
\end{tabular}

$95 \% \mathrm{CI}=95 \%$ confidence interval; PR = prevalence ratio.

* Age group, educational level, neighborhood infrastructure, moderate and severe victimization.

† Total number of replies to each question.

₹ Students who reported getting drunk during the last month, according to each variable.

$\S$ Percentages calculated based on the total number of people providing responses to each questions $\left({ }^{\dagger}\right)$.

II $p<0.05$.

still possible that some students did not reveal their true usage of alcohol or psychoactive substances or the true severity of problems related to exposure to violence, since both issues are the subject of fear and prejudice. ${ }^{28}$ Furthermore, exposure to domestic violence was not investigated, which could be another factor influencing the behavior of young people. ${ }^{26}$ These limitations may have influenced the results in terms of the prevalence of the outcomes alcohol use and drunkenness and exposure to violence.

The results of this investigation allow for the conclusion that students at public schools who admit alcohol abuse, especially those with more intense usage, are at increased risk of being the victims of community violence.

\section{Acknowledgements}

This research was partially financed by CEBRID and AAPEFATO. HMTB is CNPq researcher $1 \mathrm{C}$. SENAD/AAPEFATO provided Masters bursaries (TCM and ELB) and a scientific initiative grant (FV). We are particularly grateful to professors Silvia Benetti, Cíntia Gama and Maria Lucrecia Zavaschi for countless moments of support during the data collection and data analysis.

\section{References}

1. World Health Organization (WHO). Informe mundial sobre la violencia y la salud: resumen. Washington, D.C.: Organización Panamericana de la Salud-Oficina Regional para las Américas de la Organización Mundial de la Salud; 2002.

2. Zavaschi ML, Benetti S, Polanczyk GV, Solés N, Sanchotene ML. Adolescents exposed to physical violence in the community: a survey in Brazilian public schools. Rev Panam Salud Publica. 2002;12:327-32.

3. Higley JD. Individual differences in alcohol-induced aggression. A nonhuman-primate model. Alcohol Res Health. 2001;25: 12-9.

4. Pillon SC, O'Brien B, Piedra Chavez KA. The relationship between drugs use and risk behaviors in Brazilian university students. Rev Lat Am Enfermagem. 2005;13:1169-76.

5. Shepherd JP, Sutherland I, Newcombe RG. Relations between alcohol, violence and victimization in adolescence. J Adolesc. 2006;29:539-53.

6. Morojele NK, Brook JS. Substance use and multiple victimization among adolescents in South Africa. Addict Behav. 2006;31: 163-76.

7. Dinh-Zarr T, Goss C, Heitman E, Roberts I, DiGuiseppi C. Interventions for preventing injuries in problem drinkers. Cochrane Database Syst Rev. 2000;CD001857.

8. Orgaz Gallego MP, Segovia Jiménez M, López de Castro F, Tricio Armero MA. Alcohol consumption in Toledo schoolchildren: reasons and alternatives. Aten Primaria. 2005;36:297-302. 
9. Room R, Babor T, Rehm J. Alcohol and public health. Lancet. 2005:365:519-30.

10. Pridemore WA. Vodka and violence: alcohol consumption and homicide rates in Russia. Am J Public Health. 2002;92:1921-30.

11. Bye EK. Alcohol and violence: use of possible confounders in a time-series analysis. Addiction. 2007;102:369-76.

12. Benetti SP, Gama C, Vitolo M, da Silva MB, D'Ávila A, Zavaschi ML.Violência comunitária, exposição às drogas ilícitas e envolvimento com a lei na adolescência. Psico. 2006;37: 279-86.

13. Galduróz JC, Noto AR, Nappo SA, Carlini EA. Trends in drug use among students in Brazil: analysis of four surveys in 1987,1989, 1993 and 1997. Braz J Med Biol Res. 2004;37:523-31.

14. Galduróz JC, Noto AR, Fonseca AM, Carlini EA. V Levantamento Nacional sobre o consumo de drogas psicotrópicas entre estudantes do Ensino Fundamental e Médio da Rede Pública de ensino nas 27 capitais Brasileiras. Brasília: SENAD; 2004.

15. Richters JE, Martinez P. The NIMH Community violence project: I. Children as victims of and witness to violence. Psychiatry. 1993; 56:7-21.

16. Vermeiren R, Schwab-Stone M, Deboutte D, Leckman PE, Ruchkin V. Violence exposure and substance use in adolescents: findings from three countries. Pediatrics. 2003;111:535-40.

17. Lopes Neto AA. Bullying: comportamento agressivo entre estudantes. J Pediatr (Rio J). 2005;81:S164-72.

18. Tavares BF, Béria JU, Lima MS. Fatores associados ao uso de drogas entre adolescentes escolares. Rev Saude Publica. 2004; 38:787-96.

19. Pechansky F, Szobot CM, Scivoletto S. Uso de álcool entre adolescentes: conceitos, características epidemiológicas e fatores etiopatogênicos. Rev Bras Psiquiatr. 2004;26 Suppl $1: 14-7$.

20. Ferigolo M, Barbosa FS, Arbo E, Malysz AS, Stein AT, Barros HM. Drug use prevalence at FEBEM, Porto Alegre. Rev Bras Psiquiatr. 2004; $26: 10-6$.
21. Tavares BF, Béria JU, Silva de Lima M. Prevalência do uso de drogas e desempenho escolar entre adolescentes. Rev Saude Publica. 2001;35:150-8.

22. Overstreet, S. Exposure to community violence defining the problem and understanding the consequences. J Child Fam Stud. 2000;9:7-25.

23. Soldera M, Dalgalarrondo $P$, Correa Filho HR, Silva CA. Uso pesado de álcool por estudantes dos ensinos fundamental e médio de escolas centrais e periféricas de Campinas (SP): prevalência e fatores associados. Rev Bras Psiquiatr. 2004;26: 174-9.

24. Fagan J. Set and setting revisited: influences of alcohol and illicit drugs on the social context of violent events. In: Martin SE, editor. Alcohol and interpersonal violence: fostering multidisciplinary perspectives. NIAAA Research Monograph No. 24. NIH Pub. No. 93-3496. Bethesda, MD: National Institute on Alcohol Abuse and Alcoholism; 1993. p. 161-91.

25. Moeller FG, Dougherty DM. Antisocial personality disorder, alcohol, and aggression. Alcohol Res Health. 2001;25:5-11.

26. Springer C, Padgett DK. Gender differences in young adolescent's exposure to violence and rates of PTSD symptomatology. Am J Orthopsychiatry. 2000;70:370-9.

27. World Health Organization (WHO). Rome: alcohol and interpersonal violence. Policy Briefing. WHO Regional Office for Europe, 2005. http://www.euro.who.int/Document/ E87347.pdf. Access: 16/01/2007.

28. Minayo MC, Deslandes SF. A complexidade das relações entre drogas, álcool e violência. Cad Saude Publica. 1998;14:35-42.

Correspondence:

Taís C. Moreira

Rua Sarmento Leite, 245/325

Farmacologia/VIVAVOZ, Centro

CEP 90050-170 - Porto Alegre, RS - Brazil

Tel. : +55 (51) 3303.8764

Fax: +55 (51) 3303.8764

E-mail: tais.moreira@bol.com.br, taiscm@fffcmpa.edu.br 